\title{
Announcement
}

\section{Third International Congress on Vascular Dementia}

Prague, Czech Republic, October 23-26, 2003

Topics include:

Definitions and Diagnostic Criteria; Epidemiology; Risk Factors; Imaging; Neuropsychology; Prevention and Treatment; Vascular Factors in Alzheimer's Disease; Genetic Forms of Vascular Dementia; Amyloid Angiopathy

For further information please contact:

Secretariat: Vascular Dementia

c/o Kenes International

17, rue du Cendrier, PO Box 1726

CH-1211 Geneva 1 (Switzerland)

Tel. +41 22908 0488; Fax +41 227322850

E-Mail vascular@kenes.com

Website www.kenes.com/vascular 